\title{
ORIGINAL ARTICLE \\ Do hatchery-reared sea urchins pose a threat to genetic diversity in wild populations?
}

\begin{abstract}
M Segovia-Viadero' ${ }^{1,2}$, EA Serrão ${ }^{1}$, JC Canteras-Jordana ${ }^{3}$ and M Gonzalez-Wangüemert ${ }^{1}$
In salmonids, the release of hatchery-reared fish has been shown to cause irreversible genetic impacts on wild populations. However, although responsible practices for producing and releasing genetically diverse, hatchery-reared juveniles have been published widely, they are rarely implemented. Here, we investigated genetic differences between wild and early-generation hatchery-reared populations of the purple sea urchin Paracentrotus lividus (a commercially important species in Europe) to assess whether hatcheries were able to maintain natural levels of genetic diversity. To test the hypothesis that hatchery rearing would cause bottleneck effects (that is, a substantial reduction in genetic diversity and differentiation from wild populations), we compared the levels and patterns of genetic variation between two hatcheries and four nearby wild populations, using samples from both Spain and Ireland. We found that hatchery-reared populations were less diverse and had diverged significantly from the wild populations, with a very small effective population size and a high degree of relatedness between individuals. These results raise a number of concerns about the genetic impacts of their release into wild populations, particularly when such a degree of differentiation can occur in a single generation of hatchery rearing. Consequently, we suggest that caution should be taken when using hatchery-reared individuals to augment fisheries, even for marine species with high dispersal capacity, and we provide some recommendations to improve hatchery rearing and release practices. Our results further highlight the need to consider the genetic risks of releasing hatchery-reared juveniles into the wild during the establishment of restocking, stock enhancement and sea ranching programs.
\end{abstract}

Heredity (2016) 116, 378-383; doi:10.1038/hdy.2015.109; published online 13 January 2016

\section{INTRODUCTION}

In recent decades, there has been an increase in the release of cultivated organisms to augment overexploited populations in forestry, fisheries and wildlife management. In the case of coastal fisheries, releases of hatchery-reared juveniles have been made for three distinct purposes: restocking, stock enhancement and sea ranching (see Bell et al., 2008 for definitions). Although the genetic risks associated with these releases have long been recognized and documented (Blankership and Leber, 1995; Bell et al., 2005; Lorenzen et al., 2012), they have rarely been monitored (Laikre et al., 2010). Thus, the consequences of genetic interactions between hatcheryreared and wild individuals remain poorly understood, and are a major cause for concern in conservation genetics.

Domesticated strains of a species often differ genetically from their wild counterparts, particularly when they have been developed selectively from breeding programs over multiple generations (Champagnon et al., 2012; Lorenzen et al., 2012). In salmonids, one of the oldest and most important aquaculture taxa in the world, we know that hybridization and introgression between hatchery-reared and wild fish may contribute to a decrease in the fitness of their wild descendants. Introgression has led to an erosion of local gene pools in wild populations, and therefore to maladaptive changes in important traits (phenotypic, life history, behavioral and so on) that can be related to local adaptation and resilience to environmental risks (Waples et al., 2012 and references therein). We also know that when large numbers of hatchery-reared fish from a small broodstock are allowed to mate with wild individuals, it may reduce the total amount of genetic variation in these 'introgressed' populations. This can result in a loss of their adaptive potential, and ultimately to the risk of inbreeding depression (Ryman-Laikre effect; Christy et al., 2012).

Although salmonids and some other commercially important finfish have received a great deal of research, there is limited information about the genetic impacts of releasing hatchery-reared shellfish into the wild (Araki and Schmid, 2010). Furthermore, a majority of shellfish studies have focused almost exclusively on abalone and other molluscan species and, to date, only a few studies have been published regarding echinoids.

The purple sea urchin Paracentrotus lividus (Lamarck, 1816) (Echinodermata, Echinoidea) is a widely distributed species that occurs in shallow waters along the European coasts of the eastern Atlantic from Scotland and Ireland to the Canary Islands, and throughout the entire Mediterranean Sea. It is highly valued for its gonads in France, Spain, Italy and Greece where they are considered a delicacy (Boudouresque and Verlaque, 2013). Mainly because of the high demand from French markets, there has been widespread overexploitation of $P$. lividus populations, with steep population

${ }^{1}$ CCMAR, Universidade do Algarve, Gambelas, Faro, Portugal; ${ }^{2}$ Departamento de Ciencias del Mar y Biología Aplicada, Universidad de Alicante, Campus de San Vicente de Raspeig, Alicante, Spain and ${ }^{3}$ Departamento de Ciencias y Técnicas del Agua y del Medio Ambiente, Universidad de Cantabria, ETS de Ingenieros de Caminos, Canales y Puertos, Santander, Spain

Correspondence: M Segovia-Viadero, CCMAR, Universidade do Algarve, Gambelas, 8005-139 Faro, Portugal.

E-mail: msegoviaviadero@hotmail.com

Received 22 May 2015; revised 30 September 2015; accepted 18 November 2015; published online 13 January 2016 
declines by the early 2000s in formerly productive regions such as Brittany and the south of Ireland (Andrew et al., 2002). In Galicia (Northwest Spain), although total landings have remained relatively constant over time, several local markets have also collapsed (Fernández-Boán et al., 2012). Consequently, there have been some attempts to develop aquaculture techniques and to augment these overexploited populations through the release of hatchery-reared juveniles (Kelly and Chamberlain, 2010; Spanish National Echinoculture Plan 2010-2012; http://www.magrama.gob.es/app/jacumar/ planes_nacionales/Documentos/114_RP_CERIMAR.pdf). However, the genetic impacts of these activities have not previously been considered.

Here we investigated genetic differences between wild and early-generation hatchery-reared populations to assess whether hatcheries had been able to maintain natural levels of genetic diversity, and thus whether releasing hatchery-reared juveniles of $P$. lividus would pose a risk to wild populations. Our hypothesis was that hatchery rearing would cause a substantial reduction in genetic diversity and differentiation from wild populations because of bottleneck effects.

\section{MATERIALS AND METHODS}

\section{Sample collection}

Two hatchery samples, composed of 44 and 45 juveniles respectively, were obtained from aquaculture facilities (CIMA Marine Research Centre and Dunmanus Seafoods).

CIMA Marine Research Centre is a regional institution of the Consellería do Medio Rural e do Mar (Xunta de Galicia, Northwest Spain: http://www. medioruralemar.xunta.es/cima) that performs research and provides advisory services on marine resources and aquaculture. Although its aquaculture research is primarily focused on the development of seed-rearing methods for commercial shellfish species and the improvement of production efficiencies, CIMA has also cultured juvenile sea urchins within the framework of a recent National Plan of JACUMAR (the Spanish Mariculture Advisory Board; Echinoculture Plan 2010-2012). Large sea urchins were collected from the wild in the region of Galicia, and spawned in CIMA hatchery facilities. They were placed upside down on individual beakers, and induced to spawn using intracoelomic injection of $0.5 \mathrm{M} \mathrm{KCl}$; with this procedure hatchery managers can decide on sex ratio and individual contributions. Three to five individuals of each sex were used per batch. Gametes from each batch were mixed together in the same tank so that all pairwise mating combinations were possible (that is, a fully factorial mating design). Larval and juvenile rearing methods used at CIMA are described in the final report of the National Echinoculture Plan 2010-2012 (http://www.magrama.gob.es/app/jacumar/planes_nacionales/ Documentos/114_IF_CERIMAR.pdf). The estimated annual production was in the order of 10000 juveniles. Some of these juveniles were experimentally grown in co-culture with mussels on commercial rafts in the estuary of Vigo, others were used in mark-release-recapture experiments and the remainder was shared with fishermen's associations in Lugo (Galicia), who released them into overexploited tidal pools and shallow subtidal areas.

Dunmanus Seafoods is a commercial hatchery operating in Cork (southwest of Ireland) since the mid-1990s. Although broodstock are usually collected from local wild populations, it has recently started to retain a selection of the fastest-growing individuals for the broodstock of subsequent seasons (Kelly and Chamberlain, 2010). In Dunmanus, the routine spawning procedure uses three to six individuals of each sex. Spawning is induced using a mild thermal shock. To avoid uncontrolled fertilization, gametes from each individual are collected in individual containers, divided into at least three portions and portions are mixed in pairwise combinations (that is, a nested/partial-factorial mating scheme). The physical requirements and feeds used during larval and juvenile rearing are described in Kelly and Chamberlain (2010). Dunmanus is currently producing over 1 million juveniles of $P$. lividus per year. Once they reach a test diameter of $25 \mathrm{~mm}$, they are on-grown to market size by sea ranching.

Wild sea urchins were collected from the upper subtidal zone at four different sites in the northwestern-most region of the species' geographical range (Castropol, Cedeira and Fisterra in Northwest Spain, and Galway in West Ireland). We chose these sites because they have previously been used as sources of the above-mentioned hatchery broodstocks. The sample size consisted of 40-45 individuals per site. They were identified on the basis of external characters and then killed by freezing.

\section{DNA extraction, PCR and scoring}

For each individual, muscle from their 'Aristotle's lantern' (jaw apparatus) was removed and stored in $100 \%$ ethanol at room temperature. Genomic DNA was extracted using the alkaline lysis method (Sambrook and Russell, 2001). Nine microsatellite markers developed previously for P. lividus by Calderón et al. (2009a) were individually amplified (Pl-b, Pl-c, Pl-f, Pl-l, Pl-t, Pl-hist, $\mathrm{Pl}-15, \mathrm{Pl}-28$ and $\mathrm{Pl}-32$ ). PCRs were carried out in $25 \mu \mathrm{l}$ reactions containing $1 \mu \mathrm{l}$ (1-5 ng) of genomic DNA, 2-3.5 mM $\mathrm{MgCl}_{2}, 0.2 \mathrm{~mm}$ dNTPs, $0.12 \mu \mathrm{m}$ of each primer (using forward primers labeled with FAM or HEX (Sigma-Aldrich, St Louis, MO, USA) (Applied Biosystems, Foster City, CA, USA), $10 \times$ PCR Buffer and $1 \mathrm{U}$ of Go Taq Polymerase (Ecogen, Barcelona, Spain). Amplification conditions consisted of an initial denaturation step at $95^{\circ} \mathrm{C}$ for $3 \mathrm{~min}$, followed by 30 cycles composed of denaturation at $95^{\circ} \mathrm{C}$ for $50 \mathrm{~s}$, annealing at an optimal temperature (specified in Supplementary Table 1) for $50 \mathrm{~s}$, extension at $72{ }^{\circ} \mathrm{C}$ for $60 \mathrm{~s}$ and a final extension at $72{ }^{\circ} \mathrm{C}$ for $5 \mathrm{~min}$. PCR was modified for the loci Pl-15, Pl-hist and Pl-t by denaturing it at $95^{\circ} \mathrm{C}$ for $5 \mathrm{~min}$, followed by 8 cycles of denaturation at $92^{\circ} \mathrm{C}$ for $45 \mathrm{~s}$, annealing at $57^{\circ} \mathrm{C}$ for $45 \mathrm{~s}$, extension at $72{ }^{\circ} \mathrm{C}$ for $45 \mathrm{~s}, 25$ more cycles of denaturation at $92^{\circ} \mathrm{C}$ for $30 \mathrm{~s}$, annealing at $57^{\circ} \mathrm{C}$ for $30 \mathrm{~s}$, extension at $72{ }^{\circ} \mathrm{C}$ for $30 \mathrm{~s}$ and final extension at $72{ }^{\circ} \mathrm{C}$ for $5 \mathrm{~min}$. One of the nine loci ( $\left.\mathrm{Pl}-28\right)$ showed high persistence of missing data (PCR failure) and was thus excluded.

All PCR reactions were performed on a GeneAmp 2720 thermalcycler (Applied Biosystems). Fragment length was analyzed according to the protocols from the molecular biology service at CCMAR (Centre of Marine Sciences, Faro, Portugal) on an ABI PRISM 3130xl DNA analyzer (Applied Biosystems) using the GeneScan 500 LIZ standard. Raw allele sizes were scored using the STRand software (v. 2.4.59: http://www.vgl.ucdavis.edu/informatics/strand. php).

\section{Statistical analyses}

Data quality and genetic diversity. For each microsatellite locus and population, Hardy-Weinberg equilibrium and linkage disequilibrium were tested using GENEPOP v.4.2.2 (Rousset, 2008). Null allele frequencies were estimated using Micro-Checker v.2.2.3 (Van Oosterhout et al., 2004) and FreeNA (Chapuis and Estoup, 2007). Allele frequencies, number of alleles and unbiased expected and observed heterozygosities were calculated using ARLEQUIN v.3.5.1.2 (Excoffier and Lischer, 2010). We also calculated allelic richness using the rarefaction method implemented in HP Rare 1.0 (Kalinowski, 2005) that compensates for uneven population sample sizes. To test whether rearing practices led to a substantial loss of genetic diversity, we compared estimates of genetic diversity: number of alleles, allelic richness and gene diversity (expected heterozygosity), according to their origin $(\mathrm{H}$; hatchery and $\mathrm{W}$; wild population). The effective population size $\left(N_{\mathrm{e}}\right)$ and relatedness were also compared in order to better understand the genetic variation between wild and hatchery reared populations. $N_{\mathrm{e}}$ was estimated using the linkage disequilibrium method implemented in NeEstimator v.2 (Do et al., 2014) that includes a bias correction for dealing with missing data (Peel et al., 2013). We screened out rare alleles with frequencies below two critical values: $P_{\text {crit }}=0.05$ and $P_{\text {crit }}=0.02$, obtaining two different $N_{\mathrm{e}}$ estimates. The confidence intervals were estimated with the jackknife method described in Waples and Do (2008). Pairwise relatedness among individuals (as proportion of full-sibs) within each population was estimated by the maximum likelihood method using the software ML-Relate (Kalinowski et al., 2006). The differences among populations and groups of populations were tested using a binomial test $\left(\chi^{2}\right)$ with a significance level of $P=0.05$.

Genetic differentiation. To test whether hatchery rearing might also promote differentiation between hatchery-reared and wild populations, several approaches were used. We first calculated population-level pairwise genetic differentiation as $F_{\mathrm{ST}}$ (Weir and Cockerham, 1984) in ARLEQUIN v.3.5.1.2, for which statistical significance was determined by 10000 random permutations 
of the original data set. $F_{\mathrm{ST}}$ values (Weir, 1996) were recalculated in FreeNA using the 'Excluding Null Alleles' method (Chapuis and Estoup, 2007) to correct the positive bias induced by the presence of null alleles on $F_{\mathrm{ST}}$ estimation. ARLEQUIN was also used to partition the total genetic variation within populations, and between and within groups of populations using analysis of molecular variance.

We used the Bayesian clustering method implemented in the software STRUCTURE v.2.3.4 (Pritchard et al., 2000) to identify the number of distinct genetic clusters $(K)$ in our data set. For this, we chose a model that assumed admixture between populations and correlated allele frequencies, and carried out 10 independent runs for values $K=1-6$. Each run used 500000 Markov chain Monte Carlo generations following a burn-in of 10000 steps. Results were uploaded to STRUCTURE HARVESTER (Earl and von Holdt, 2011) to identify the most likely value of $K$ by two ad hoc methods: the modal value of $\Delta K$ (Evanno et al. 2005) and the $K$ value that maximizes the log probability of data, $\operatorname{Ln} P(D)$ (Pritchard et al., 2000). To visualize the cluster structure, we performed a principal component analysis (PCA) using the ADEgenet package (Jombart, 2008) with R software (R Foundation for Statistical Computing, Vienna, Austria). PCA has become a standard tool to detect genetically differentiated groups (Jombart, 2008); its advantage is that it is independent of any genetic hypotheses such as Hardy-Weinberg equilibrium or linkage disequilibrium.

\section{RESULTS}

\section{Data quality and genetic diversity}

A total of 258 individuals were genotyped. Five out of the eight microsatellite loci showed Hardy-Weinberg disequilibrium with an excess of homozygotes in most of the studied populations (Supplementary Table 1). Only the Pl-b locus presented estimated null allele frequency of $>0.2$ (Supplementary Table 1 ). Removal of this locus did not change the results obtained, and hence it was retained in subsequent analyses. Out of 168, 48 pairwise combinations of loci showed significant linkage disequilibrium (data not shown). When the samples from the hatcheries (CIMA and Dunmanus; H1; $\mathrm{H} 2$ ) were excluded, only 6 pairwise combinations exhibited significant linkage disequilibrium.

All loci were highly polymorphic: the total number of alleles (A) per locus ranged from 13 (Pl-f) to 42 (Pl-hist). Although allelic richness (Ar) was high across all loci and populations (with the exception of Pl-32 and Pl-f), both hatchery populations showed a considerable loss of alleles compared with wild populations (Supplementary Table 1). In fact, we found that a relatively high number of alleles that were observed in all the wild populations were not detected in the CIMA (H1, 18 alleles) and Dunmanus (H2, 23 alleles) hatcheries.

Estimations of genetic diversity as allelic richness and gene diversity (expected heterozygosity) per population $\left(\mathrm{Ar}, H_{\mathrm{e}}\right)$ revealed the highest values in the four wild populations (Table 1). Values of gene diversity remained high in the two hatchery populations but allelic richness declined considerably (Table 1); this may be indicative of a bottleneck. Estimated effective population sizes $\left(N_{\mathrm{e}}\right)$ for both hatcheries were very low, varying from 9 individuals to 19 individuals $\left(P_{\text {crit }}=0.05\right.$; Table 2$)$. The four wild populations displayed $N_{\mathrm{e}}$ confidence intervals that approached infinity (Table 2, negative values correspond to estimates of $N_{\mathrm{e}}$ that approach infinity: Do et al., 2014). Estimation of relatedness showed high genetic similarity between pairs of individuals within the hatchery-reared populations (proportions of full-sibs; $\mathrm{H} 1=5.52 \%$ and $\mathrm{H} 2=8.51 \%$ ). The analysis conducted to compare whether relatedness was greater within hatcheries than within wild populations revealed larger proportions of full-sibs for both hatchery populations against wild ones $\left(\chi^{2} ; \mathrm{H} 1\right.$ vs $\mathrm{W}=33.32$ and $\mathrm{H} 2$ vs $\left.\mathrm{W}=52.08 ; P \leqslant 0.05\right)$.
Table 1 Characteristics of the studied populations, including the number of individuals sampled $(N)$, total number of alleles $(A)$, allelic richness $(\mathrm{Ar})$, mean expected $\left(H_{\mathrm{e}}\right)$ and mean observed $\left(H_{0}\right)$ heterozygosity, $F_{I S}$ and Hardy-Weinberg equilibrium deviation test (HWE)

\begin{tabular}{llllllllll}
\hline $\begin{array}{l}\text { Population } \\
\text { codes }\end{array}$ & $\begin{array}{l}\text { Sampling } \\
\text { locations }\end{array}$ & $\mathrm{N}$ & $A$ & Ar & $\mathrm{H}_{e}$ & $\mathrm{H}_{0}$ & $\mathrm{~F}_{/ S}$ & HWE \\
\hline
\end{tabular}

Hatcheries

$\mathrm{H} 1$

CIMA Research Centre, $44114 \quad \begin{array}{lllll}42.93 & 0.81 & 0.66 & 0.20\end{array}$ *** Spain

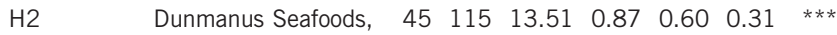
Ireland

$\begin{array}{ccccccccc}\begin{array}{c}\text { Wild populations } \\ \text { W1 }\end{array} & \text { Castropol, Spain } & 43 & 162 & 18.68 & 0.90 & 0.71 & 0.21 & * * * \\ \text { W2 } & \text { Cedeira, Spain } & 42 & 160 & 18.24 & 0.88 & 0.66 & 0.25 & * * * \\ \text { W3 } & \text { Fisterra, Spain } & 43 & 160 & 18.47 & 0.89 & 0.62 & 0.31 & * * * \\ \text { W4 } & \text { Galway, Ireland } & 41 & 152 & 17.90 & 0.90 & 0.68 & 0.25 & * * *\end{array}$

Level of significance of the HWE deviation test is designated by asterisks (***P$P \leqslant 0.001)$.

\section{Genetic differentiation}

Significant differentiation was observed between hatcheries and wild populations based on $F_{\mathrm{ST}}$ estimates (Table 3). Wild populations, although geographically distant (W1, W2 and W3 in Northwest Spain and W4 in West Ireland), were not genetically divergent with very low values of $F_{\mathrm{ST}}$ ranging from 0.001 to $0.003(P>0.05)$. On the contrary, the two hatcheries, $\mathrm{H} 1$ and $\mathrm{H} 2$, showed significant differences between each other $\left(F_{\mathrm{ST}}=0.082 ; P<0.001\right)$. H1 had the highest values of pairwise $F_{\mathrm{ST}}$ with all of the wild populations (W1, W2, W3 and W4) ranging from 0.057 to $0.065(P<0.001)$. The 'Excluding Null Alleles' correction method obtained very similar estimates of $F_{\mathrm{ST}}$ (Supplementary Table 2). Analysis of molecular variance tests showed that genetic differences within groups of populations $(2.44 \%$, $P<0.001)$ explained larger variance than those observed between groups of populations $(1.02 \%, P=1.20)$, but most of the variance was explained by the differences among individuals $(96.54 \%, P<0.001)$. Bayesian clustering (STRUCTURE) revealed $K=3$ as the most likely number of genetic clusters; clusters $K=1$ and $K=2$ corresponded to the two hatcheries, $\mathrm{H} 1$ and $\mathrm{H} 2$, respectively and cluster $K=3$, to all the wild populations, W1-4 (Figure 1 and Supplementary Figures 1 and 2). The PCA differentiated the two hatchery populations on the first axis (Figure 2). The second axis of the PCA separated wild from hatchery populations and expressed the genetic variability within the two hatchery populations (Figure 2).

\section{DISCUSSION}

Hardy-Weinberg disequilibrium and absence of structure in the wild studied populations

We observed significant deviations from Hardy-Weinberg equilibrium because of heterozygote deficiency in the eight studied loci, but not at all localities. It is unlikely that null alleles are the main cause of these deviations, because only one of these loci had a high frequency of null alleles. These results are consistent with those found in P. lividus populations from Catalonia (Northeast Spain, Calderón et al., 2009a,b; Calderón and Turon, 2010), where authors revealed that positive assortative mating could partially explain the observed Hardy-Weinberg disequilibrium. Encoded proteins on the surface of sperm and eggs from echinoids have already been found to mediate the compatibility of gametes at fertilization, and to act as an important mechanism in 
Table 2 Estimated effective population sizes (and their confidence intervals (Cls)) for each population

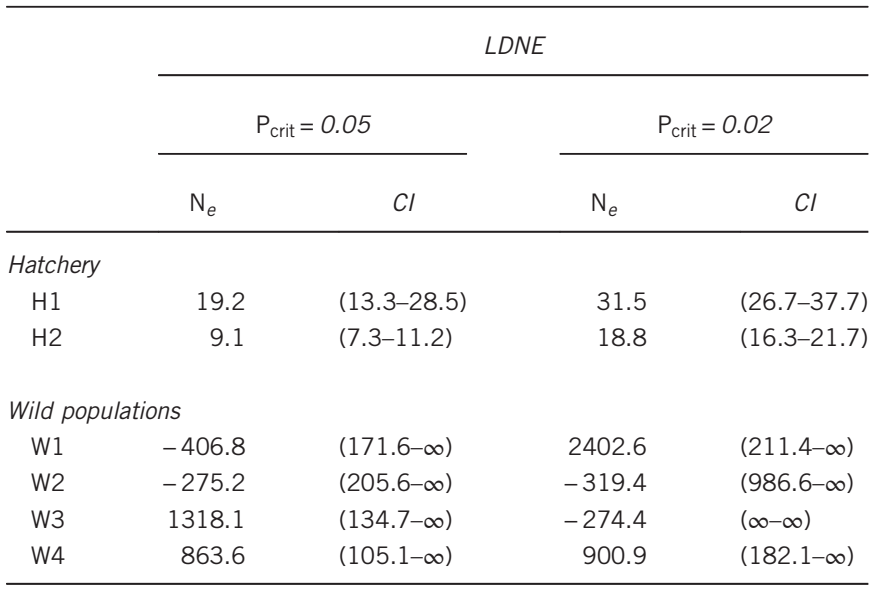

Table 3 Matrix of pairwise $F_{\mathrm{ST}}$ between all populations

\begin{tabular}{lllllll}
\hline & $H 1$ & $H 2$ & $W 1$ & W2 & W3 & W4 \\
\hline H1 & 0 & & & & & \\
H2 & 0.083 & 0 & & & & \\
W1 & $\mathbf{0 . 0 5 8}$ & $\mathbf{0 . 0 2 4}$ & 0 & & & \\
W2 & $\mathbf{0 . 0 6 6}$ & $\mathbf{0 . 0 2 1}$ & 0.002 & 0 & & \\
W3 & $\mathbf{0 . 0 6 3}$ & $\mathbf{0 . 0 2 2}$ & 0.001 & 0.002 & 0 & \\
W4 & $\mathbf{0 . 0 5 9}$ & $\mathbf{0 . 0 2 1}$ & 0.002 & 0.006 & 0.004 & 0
\end{tabular}

Population codes are explained in Table 1 . Statistically significant values $(P \leqslant 0.05)$ are indicated in bold.

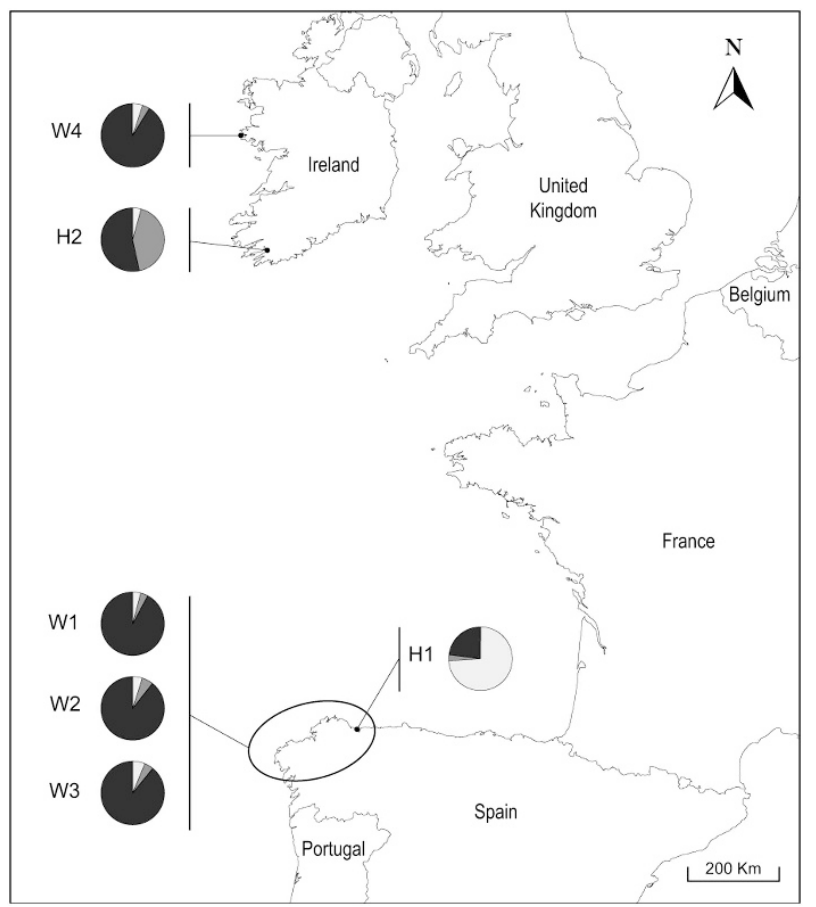

Figure 1 Graphical summary of the STRUCTURE analysis results for $K=3$. The proportions of membership of each cluster are represented in pie charts for each sampled population: light gray for cluster $K=1$, dark gray for cluster $K=2$ and black for cluster $K=3$. their reproductive success (Calderón et al., 2009c). Other ecological processes, such as recent admixture or temporal Wahlund effect, have also been commonly associated with heterozygote deficiency in sea urchins (Addison and Hart, 2004; Casilagan et al., 2013). These processes may also contribute to the significant deviations from Hardy-Weinberg equilibrium found in our samples. Indeed, a recent study by Calderón et al. (2012) has revealed genetic differentiation among cohorts of recruits in $P$. lividus that was interpreted as the consequence of a high variance in reproductive or recruitment success in this sea urchin species (Boudouresque and Verlaque, 2013).

The absence of significant differentiation between the studied wild populations (W1, Castropol; W2, Cedeira; W3, Fisterra; and W4, Galway) suggests an absence of barriers to gene flow across these Atlantic coastlines ranging from north Spain to Ireland. These results are in agreement with most of the previous mitochondrial DNA phylogeographic studies in this species that suggest a panmixia scenario in the Atlantic basin (Duran et al., 2004; Calderón et al., 2008; Maltagliati et al., 2010). This pattern can be easily explained by the high potential for dispersal in this species: although its adult life stage is sedentary, it can disperse long distances over its larval period of 23-29 days (Boudouresque and Verlaque, 2013).

Differentiation between wild and early-generation hatchery-reared populations

As in most echinoids, wild populations of P. lividus in the northwestern Atlantic region had a high degree of genetic diversity (Adison and Hart, 2004; Banks et al., 2007; Casilagan et al., 2013). The results obtained in this study revealed that although hatchery populations were able to maintain high gene diversity (expected heterozygosity), they had considerably lower allelic richness relative to wild populations. Such a drop in allelic richness (but not in gene diversity) is likely to occur shortly after a population bottleneck. If only a few individuals are used as the broodstock for a reared population, then this would be expected to leave a bottleneck signature. In a recent review, Araki and Schmid (2010) found that losses of allelic richness are more common than those of heterozygosity in early generations of hatchery-reared populations. In addition, we observed that hatchery-reared populations had a significant decrease in effective population size $\left(N_{\mathrm{e}}\right)$, and a higher degree of relatedness. A small effective population size implies that random genetic drift has a greater influence than natural selection, and therefore that favorable alleles can decline in frequency and deleterious alleles may increase by chance. The challenge for aquaculture and restocking/stock enhancement programs is to avoid these genetic changes in subsequent generations, and more specifically, the loss of allelic diversity, the accumulation of new deleterious mutations and inbreeding depression. Consequently, Agatsuma et al. (2004, 2013) have recently reported responsible stock enhancement practices for Strongylocentrotus intermedious in Japan (that is, using hatchery-reared sea urchins derived from seven spawning events involving almost 600 parents). The two hatcheries studied here ( $\mathrm{H} 1$ and $\mathrm{H} 2)$ had very small $N_{\mathrm{e}}$ (19 and 9, respectively; 95\% confidence interval), suggesting that they originated from only a few spawning individuals. We further observed that Dunmanus (H2) had a slight excess of full-sib proportion that corroborated the smaller effective population size $\left(N_{\mathrm{e}}\right)$. In both cases, $N_{\mathrm{e}}$ was lower than the minimum value recommended by most authors to avoid the aforementioned genetic problems in the short term $\left(N_{\mathrm{e}}=50\right.$; Franklin, 1980; Jamieson and Allendorf, 2012).

Overall, our analyses ( $F_{\mathrm{ST}}$, Bayesian cluster and PCA) revealed three distinct clusters: a single cluster for each hatchery-reared 


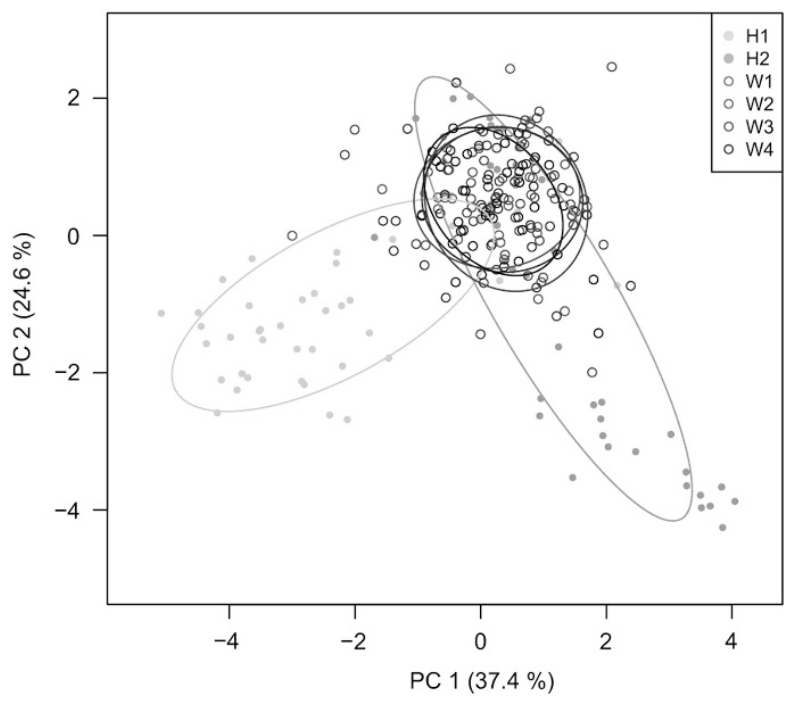

Figure 2 Ordination diagram of the PCA. Axes 1 and 2 are the first and second principal components of variability. Each gray point represents an individual, coded by origin (filled $=$ hatcheries and open=wild populations). Ellipses represent $95 \%$ confidence interval for each of the six studied populations.

population ( $\mathrm{H} 1$ and $\mathrm{H} 2$ ) and third comprising the four wild populations (W1, W2, W3 and W4). The genetic divergence among hatchery populations, and between hatchery and wild populations, indicates that the hatcheries are not representative of the wild gene pool, most likely as a result of bottleneck effects together with domestication selection. The present study further demonstrates that genetic differentiation can even occur in the first generation of a hatchery-reared population that is created using wild broodstock (as is the case for H1). These findings are consistent with previous observations in other urchin or shellfish hatcheries (Natsukari et al., 1995; Evans et al., 2004) that found that a single generation of hatchery rearing was enough to produce an offspring genetically different from its broodstock.

In conclusion, rearing practices in the hatcheries studied here resulted in populations that differ genetically from wild ones. As these hatcheries were not able to protect the cultured populations from losses of genetic diversity, increases in relatedness and significant changes in allele frequencies, there may be serious concerns about the genetic impacts of their release into the wild, as they may cause a reduction in genetic diversity and fitness in recipient populations. As a result, we strongly recommend that the potential genetic risks of releasing hatchery-reared sea urchins should be considered from the start of the rearing process, particularly in the hatchery step. In general, it is important to maintain a large $N_{\mathrm{e}}$ throughout the process, because although domestication cannot be avoided, additional detrimental changes arising from increased genetic drift can be prevented. However, the requirements may differ depending on the primary objective of the release of hatchery-reared sea urchins.

Stock enhancements can be used to overcome recruitment limitations by augmenting the supply of juveniles, even when there is a good number of spawning adults. In accordance with the Ryman-Laikre effect, large wild populations are at the greatest threat of proportional reductions in $N_{\mathrm{e}}$ (Ryman and Laikre, 1991). It is therefore recommended that in stock enhancement projects, broodstock $N_{\mathrm{e}}$ should be maintained at a high level $(>100)$, or that offspring from hatcheryreared individuals comprise only a small percentage of the overall population in the next generation $(<10 \%)$ (for examples see Waples et al., 2012). On the contrary, restocking attempts to restore depleted populations are likely to be effective only if they result in substantial increases in the spawning biomass; to achieve this goal, they might need to double the number of adults in the wild. In these circumstances, various scenarios with moderate broodstock $N_{\mathrm{e}}$ and contribution of hatchery-reared individuals to the next generation need to be considered carefully in order to achieve a cost-effective balance, and to avoid reducing the wild $N_{\mathrm{e}}$ by more than half (Waples et al., 2012).

The importance of maintaining a high effective population size $\left(N_{\mathrm{e}}\right)$ in the broodstock should be emphasized. Thus, it is recommended that the aforementioned minimum value $N_{\mathrm{e}}=50$ should at least be doubled to 100, as suggested by Frankham et al. (2013) (assuming an accumulated reduction of up to $10 \%$ in total fitness after 5 generations). Here, it is important to remember that the proportion of broodstock that effectively contributes to the next generation is generally less than the total number of parents (Tave, 1999), and hence 100 broodstock parents may not be sufficient to reach $N_{\mathrm{e}}=100$. A carefully planned breeding program can help to maximize the broodstock $N_{\mathrm{e}}$, that is, by equalizing family sizes or breeding schemes to minimize kinship. We also recommend the use of wild broodstocks from local sources, because they are expected to produce hatchery populations that represent a lower genetic risk to wild populations (Bell et al., 2005; Baskett et al., 2013). Each broodstock should be replaced for every new batch of juveniles or at least on a regular basis, so that successive releases of juveniles derived from different broodstocks will increase the overall $N_{\mathrm{e}}$.

\section{DATA ARCHIVING}

Allele frequency data available from the Dryad Digital Repository: http://dx.doi.org/10.5061/dryad.tn04d.

\section{CONFLICT OF INTEREST}

The authors declare no conflict of interest.

\section{ACKNOWLEDGEMENTS}

We are grateful to JL Catoira Gómez, the founder and coordinator of the Spanish National Echinoculture Plan 2010-2012, for his assistance throughout the project. We also thank D Martínez Patiño and J Ojea Martínez (CIMA Marine Research Centre, Consellería do Medio Rural e do Mar, Xunta de Galicia) for access to the CIMA aquaculture facilities and for their kind cooperation. Logistics and field assistance were provided by A Tubio (Departamento de Biología Animal, Biología Vegetal y Ecología, Universidad de A Coruña), JF Carrasco Fidalgo, S de la Uz Díaz (CEP Fisheries Research Centre, Consejería de Agroganadería y Recursos Autóctonos, Gobierno del Principado de Asturias), JM González Irusta and FJ Ansorena (Departamento de Ciencias y Técnicas del Agua y del Medio Ambiente, Universidad de Cantabria). We thank J Chamberlain (Dunmanus Seafoods) and C Hannon (Connemara Abalone) for providing hatchery-reared and wild specimens from Ireland. We also thank two anonymous reviewers for their constructive comments that helped us to improve the quality of the manuscript, and NC Marchant for language revision. This work was funded by the Spanish Mariculture Advisory Board (JACUMAR) and the Regional Government of Cantabria as part of the National Echinoculture Plan 2010-2012 (Plan_114_RP_CERIMAR), by the EU FP7 (ASSEMBLE Grant Agreement No. 227799) and by the Portuguese Foundation for Science and Technology (FCT) through project PTDC/MAR/119363/2010 (http://www.ccmar.ualg.pt/cumfish/) and the FCT postdoctoral (SFRH/BPD/70689/2010) and FCT investigator (IF/ 00998/2014) grants to MGW.

Addison JA, Hart MW (2004). Analysis of population genetic structure of the green sea urchin (Strongylocentrotus droebachiensis) using microsatellites. Mar Biol 144: 243-251. 
Agatsuma Y, Sakai Y, Andrew NL (2004). Enhancement of Japan's sea urchin fisheries. In: Lawrence JM, Guzmán $O$ (eds) Sea Urchins: Fisheries and Ecology, Proceedings of the International Conference on Sea-Urchin Fisheries and Aquaculture. DEStech Pub Inc.: Lancaster. pp 18-36.

Agatsuma Y (2013). Stock enhancement. In: Lawrence JM (ed) Sea Urchins: Biology and Ecology, 3rd edn, vol. 38. Elsevier: Oxford. pp 213-224.

Andrew NL, Agatsuma Y, Ballesteros E, Bazhin AG, Creaser EP, Barnes DKA et al. (2002). Status and management of world sea urchin Fisheries. Oceanogr Mar Biol Annu Rev 40: 343-425.

Araki H, Schmid C (2010). Review: Is hatchery stocking a help or a harm? Evidence, limitations and future directions in ecological and genetic surveys. Aquaculture 308: S2-S11.

Banks SC, Piggott MP, Williamson JE, Bové U, Holbrook NJ, Beheregaray LB (2007). Oceanic variability and coastal topography shape genetic structure in a long-dispersing sea urchin. Ecology 88: 3055-3064.

Baskett ML, Burgess SC, Waples RS (2013). Assessing strategies to minimize unintended fitness consequences of aquaculture on wild populations. Evol App/ 6: 1090-1108.

Bell JD, Rothlisberg PC, Munro JL, Loneragan NR, Nash WJ, Ward RD et al. (2005). Restocking and stock enhancement of marine invertebrate fisheries. Adv Mar Biol 49: $1-370$.

Bell JD, Leber KM, Blankenship HL, Loneragan NR, Masuda R (2008). A new era for restocking, stock enhancement and sea ranching of coastal fisheries resources. Rev Fish Sci 16: 1-9

Blankenship HL, Leber KM (1995). A responsible approach to marine stock enhancement. Am Fish Soc Symp 15: 167-175.

Boudouresque CF, Verlaque M (2013). Paracentrotus lividus. In: Lawrence JM (ed) Sea Urchins: Biology and Ecology, 3rd edn, vol. 38. Elsevier: Oxford. pp 297-327.

Calderón I, Giribet G, Turon X (2008). Two markers and one history: phylogeography of the edible common sea urchin Paracentrotus lividus in the Lusitanian region. Mar Biol 154: 137-151.

Calderón I, Turon X, Pascual M (2009a). Isolation of nine nuclear microsatellites in the common Mediterranean sea urchin, Paracentrotus lividus (Lamarck). Mol Ecol Resour 9 : 1145-1147.

Calderón I, Palacin C, Turon X (2009b). Microsatellite markers reveal shallow genetic differentiation between cohorts of the common sea urchin Paracentrotus lividus (Lamarck) in northwest Mediterranean. Mol Ecol 18: 3036-3049.

Calderón I, Turon X, Lessios HA (2009c). Characterization of the sperm molecule bindin in the sea urchin genus Paracentrotus. J Mol Evol 68: 366-376.

Calderón M, Turon X (2010). Temporal genetic variability in the Mediterranean common sea urchin Paracentrotus lividus. Mar Ecol Prog Ser 408: 149-159.

Calderón I, Pita L, Brusciotti S, Palacín C, Turon X (2012). Time and space: genetic structure of the cohorts of the common sea urchin Paracentrotus lividus in Western Mediterranean. Mar Biol 159: 187-197.

Casilagan ILN, Juinio-Meñez MA, Crandall ED (2013). Genetic diversity, population structure, and demographic history of exploited sea urchin populations (Tripneustes gratilla) in the Philippines. J Exp Mar Biol Ecol 449: 284-293.

Champagnon J, Elmberg J, Guillemain M, Gauthier-Clerc M, Lebreton JD (2012) Conspecifics can be aliens too: a review of effects of restocking practices in vertebrates. J Nat Conserv 20: 231-241.

Chapuis MP, Estoup A (2007). Microsatellite null alleles and estimation of population differentiation. Mol Biol Evol 24: 621-631.

Christie MR, Marine ML, French RA, Waples RS, Blouin MS (2012). Effective size of a wild salmonid population is greatly reduced by hatchery supplementation. Heredity 109 254-260.

Do C, Waples RS, Peel D, Macbeth GM, Tillett BJ, Ovenden JR (2014). NeEstimator v2: re-implementation of software for the estimation of contemporary effective population size (Ne) from genetic data. Mol Ecol Resour 14: 209-214.

Duran S, Palacin C, Becerro MA, Turon X, Giribet G (2004). Genetic diversity and population structure of the commercially harvested sea urchin Paracentrotus lividus (Echinodermata: Echinoidea). Mol Ecol 13: 3317-3328.

Earl DA, von Holdt BM (2011). STRUCTURE HARVESTER: a website and program for visualizing STRUCTURE output and implementing the Evanno method. Conserv Genet Resour 4: 359-361.

Evanno G, Regnaut S, Goudet J (2005). Detecting the number of clusters of individuals using the software STRUCTURE: a simulation study. Mol Ecol 14: 2611-2620.
Evans B, Bartlett J, Sweijd N, Cook P, Elliott NG (2004). Loss of genetic variation at microsatellite loci in hatchery produced abalone in Australia (Haliotis rubra) and South Africa (Haliotis midae). Aquaculture 233: 109-127.

Excoffier L, Lischer HE (2010). Arlequin suite ver 35: a new series of programs to perform population genetics analyses under Linux and Windows. Mol Ecol Resour 10: 564-567.

Fernández-Boán M, Fernández L, Freire J (2012). History and management strategies of the sea urchin Paracentrotus lividus fishery in Galicia (NW Spain). Ocean Coast Manag 69: 265-272.

Frankham R, Brook BW, Bradshaw CJ, Traill LW, Spielman D (2013). 50/500 rule and minimum viable populations: response to Jamieson and Allendorf. Trends Ecol Evol 28 187-188.

Franklin IR (1980). Evolutionary change in small populations. In: Soule ME, Wilcox BA (eds) Conservation Biology: An Evolutionary-Ecological Perspective. Sinauer Associates Inc: Sunderland. pp 135-149.

Jamieson IG, Allendorf FW (2012). How does the 50/500 rule apply to MVPs? Trends Ecol Evol 27: 578-584.

Jombart T (2008). Adegenet: a R package for the multivariate analysis of genetic markers. Bioinformatics 24: 1403-1405.

Kalinowski ST (2005). Hp Rare 1.0: a computer program for performing rarefaction on measures of allelic richness. Mol Ecol Notes 5: 187-189.

Kalinowski ST, Wagner AP, Taper ML (2006). ML-RELATE: a computer program for maximum likelihood estimation of relatedness and relationship. Mol Ecol Notes 6 : 576-579.

Kelly MS, Chamberlain J (2010). Recent advances in sea urchin aquaculture and enhancement in Scotland and Ireland. Bull Aquacul Assoc Canada 108-1: 23-29.

Laikre L, Schwartz MK, Waples R, Ryman N (2010). Compromising genetic diversity in the wild: unmonitored large-scale release of plants and animals. Trends Ecol Evol 25 520-529.

Lorenzen K, Beveridge MCM, Mangel M (2012). Cultured fish: integrative biology and management of domestication and interactions with wild fish. Biol Rev 87: 639-660.

Maltagliati F, Di Giuseppe G, Barbieri M, Castelli A, Dini F (2010). Phylogeography and genetic structure of the edible sea urchin Paracentrotus lividus (Echinodermata: Echinoidea) inferred from the mitochondrial cyto-chrome b gene. Biol J Linn Soc 100: 910-923.

Natsukari Y, Tanaka N, Chung SC, Hirayama K (1995). A genetic comparison among three groups (wild populations, artificial seed populations, and mixed populations) of a sea urchin Pseudocentrotus depressus: a preliminary report. Proceedings of the 22nd US-Japan Aquaculture Panel Symposium: Interactions between cultured species and naturally occurring species in the environment, University of Alaska.

Peel D, Waples RS, Macbeth GM, Do C, Ovenden JR (2013). Accounting for missing data in the estimation of contemporary genetic effective population size $(\mathrm{Ne}) . \mathrm{Mol} E \mathrm{Col}$ Resour 13: 243-253.

Pritchard JK, Stephens M, Donnelly P (2000). Inference of population structure using multilocus genotype data. Genetics 155: 945-959.

Rousset F (2008). Genepop'007: a complete reimplementation of the Genepop software for Windows and Linux. Mol Ecol Resour 8: 103-106.

Ryman N, Laikre L (1991). Effects of supportive breeding on the genetically effective population size. Conserv Biol 5: 325-329.

Sambrook J, Russell DW (2001). Molecular Cloning: A Laboratory Manual, 3rd edn. Cold Spring Harbor Laboratory Press: New York.

Tave D (1999). Inbreeding and brood stock management. FAO Fisheries Technical Paper No. 392

Van Oosterhout C, Hutchinson WF, Wills DPM, Shipley P (2004). MICRO-CHECKER: software for identifying and correcting genotyping errors in microsatellite data. $\mathrm{Mol} E \mathrm{EO}$ Notes 4: 535-538.

Waples RS, Do C (2008). LDNE: A program for estimating effective population size from data on linkage disequilibrium. Mol Ecol Resour 8: 753-756.

Waples R, Hindar K, Hard J (2012). Genetic Risks Associated with Marine Aquaculture. NOAA Tech Memo NMFS-NWFSC-119.

Weir BS, Cockerham CC (1984). Estimating F-statistics for the analysis of population structure. Evolution 38: 1358-1370.

Weir BS (1996). Genetic Data Analysis II: Methods for Discrete Population Data Analysis, 2nd edn. Sinauer Associates Inc.: Sunderland.

Supplementary Information accompanies this paper on Heredity website (http://www.nature.com/hdy) 